\title{
KONTRIBUSI KH MUNAWWAR ADNAN KHOLIL GRESIK TERHADAP PENDIDIKAN ISLAM
}

\author{
Muhammad Anas Ma`arif \\ Institut Pesantren KH Abdul Chalim Mojokerto \\ anasdt16@gmail.com \\ Nur Silva Nabila \\ Universitas Islam Negeri Sunan Ampel Surabaya
}

\begin{abstract}
Abstrak
Pesantren sebagai indegeneous culture mampu menciptakan tradisi-tradisi dan karya-karya yang unik. Terciptanya suatu pesantren adalah disebabkan oleh kegigihan pendirinya yaitu Kiai. Pesantren akan tetap menjadi sebuah referensi pendidikan apabila sistem dan manajemen pesantren dikelola dengan baik. Pentingnya melakukan penelitian naratif dari Kiai Munawwar adalah karena kepakaranya dalam mengelola pendidikan dan menciptakan karya-karya yang banyak diberbagai bidang ilmu. Hal ini belum banyak yang menulis tentang kiai Munawwar. Penelitian ini menggunakan penelitian historisfilosofis dengan menarasikan tokoh, karya dan biografinya serta menganalisis kontribusinya dalam pendidikan Islam. Tujuan dari penelitian ini adalah untuk mendeskripsikan dan menganalisis kiprah dan kontribusi Kiai Munawwar Kholil Gresik terhadap pendidikan Islam khususnya pesantren dan pengembangan karir santri. Penelitian ini menghasilkan: 1) Kiai Munawwar memberikan kontribusi secara maksimal di Gresik melalui pendidikan formal, non formal dan pendidikan life skill bagi santri-santrinya. 2) karyakarya yang telah ditulis mampu dijadikan sebagai kurikulum pendidikan pesantren 3) pendidikan life skill sebagai sarana khidmah di pesantren. 4) Tujuan pendidikan pesantren membentuk uluma dan konglomerat yang dermawan 5) metode pendidikan dengan bercerita (kisah) Rekomendasi: Penelitian selanjutnya bisa meneliti karya-karya Kiai Munawwar dari berbagai perspektif atau penelitian biografi secara mendalam.

Kata Kunci: KiaiMunawwar, Pendidikan Islam, Kontribusi
\end{abstract}

\section{Abstract}

Pesantren as an indigenous culture is able to create unique traditions and works. The creation of a pesantren is caused by the persistence of its founder, the Kiai. The pesantren will remain an educational reference if the pesantren system and management are well managed. The importance of conducting narrative research from Kiai Munawwar is because of his expertise in managing education and creating works in many fields of science. This has not been much written about the Kiai Munawwar. This study uses philosophical historical research by narrating the characters, works, and biography and analyzing their contribution to Islamic education. The purpose of this research is to describe and analyze the gait and contribution of Kiai Munawwar Kholil Gresik to Islamic education, especially pesantren and the development of students' careers. This research resulted in: 1) Kiai Munawwar made a maximum contribution in Gresik through formal, nonformal education and life skills education for his students. 2) the works that have been written can be used as a pesantren education curriculum 3) life skill education as a means of (khidmah) in the pesantren. 4) The aim of pesantren education is by forming ulama and, generous tycoons 5) Educational methods by telling stories (history). Recommendation: Future research can examine Kiai Munawwar's works from various perspectives or in-depth biographical research.

Keywords:KiaiMunawwar, Islamic education, Contribution. 


\section{PENDAHULUAN}

Gresik merupakan kota yang berada di jawa timur dengan julukan 'Gresik kota santri' (Kompasiana, 2018). Branding tersebut sebenarnya bukan tanpa alasan karena banyaknya makam bersejarah yang disebut Wali Songo (wali sembilan)(Amanda, 2016; Faridatin, 2016). Dantaranya adalah terdapat makam Sunan Maulana Malik Ibrahim, dan Sunan Giri (Sunyoto, 2016). Dari sejarah juga disebutkan bahwa pesantren pertama berdiri berada di Gresik yang dikomandoi oleh Sunan Maulana Malik Ibrahim (Dhofier, 2011; Nasir \& Abdushomad, 2005; Ramayulis, 2012).

Sejarah tersebut melekat dengan julukan gresik sebagai kota santri. Dan hal tersebut juga dibuktkan banyaknya pondok pesantren yang turut meneruskan tradisi pendidikan pesantren. Dari data yang dihimpun oleh pemerintah Gresik terdapat 65 pondok pesantren(Counter_webgresik, 2016) bahkan terdapat pesantren yang berusia lebih dari 200 tahun yaitu Pesantren Qomaruddin tahun 1775 (Chairudin, 2017) dan pondok pesantren Maskumambang Gresik 1896 (Sayono, 2005). Dengan banyaknya pesantren di Gresik serta bukti sejarah seperti makam-makam tua hal itu tidak terlepas dari peran seorang ulama`, dan kiai yang berjuang untuk melestarikan tradisi (Takdir, 2016; Wasid \& Mahsun, 2018).

Perjuangan sorang Kiai harusnya bisa diabadikan oleh penulis-penulis yang bisa mengenang dan meneladani sejarah dan perjuangan Kiai. Seperti halnya beberapa historis perjuangan Kiai Bashori Alwi yang ditulis oleh Abdul Malik Karim (Amrullah, 2013b) Amarullah bahwa Kiai Bashori berjuang mengembangkan pesantren dengan menulis (karya tulis). Perjuangan Kiai Maskyur Cirebon dengan menentang kolonialisme dan mengajarkan pendidikan kepada masyarakat sekitar (Syafaah, 2016). Wasid juga menulis tentang kontribusi KH Hamid Pasuruan dalam memperjuangankan agama dan pesantren dengan tasawuf (Wasid \& Mahsun, 2018). Abdul Kadir Riyadi menulis tentang pemikiran konsep manusia pada apa yang telah ditulis oleh Kiai Asrori Surabaya mursid Tarekat Qodiriyah Naqsabandiyah (Riyadi, 2017). Dan modernisasi pendidikan yang dilakukan oleh KH Zarkasyi serta upayanya dalam moderasi Islam (As'ad, 2015; Zarkasyi, 2018).

Dari berbagai bukti sejarah dan tulisan tersebut untuk menjadi teladan kelak maka penulis tergelitik untuk menulis tentang 'kontribusi $\mathrm{KH}$ Munawwar Kholil Gresik pada pendidikan Islam'. Penulis menganggap penelitian ini penting karena KH Munawwar Gresik merupakan Kiai yang mempunyai karya banyak, kiai yang ahli di bidang tasawuf, kiai yang berjuang untuk masyarakat dengan mendirikan pendidikan formal, dan informal dan kiai yang mempunyai sanad keilmuan yang tersambung hingga Rasulallah Saw (Ernawati, 2015). karena pentingnya meneladani perjuangan Kiai dengan menuliskan perjuangan dan kontribusinya agar kelak tidak hanya cerita 
Terjemah: The Contribution Of Kiai Munawwar Adnan Kholil Gresik On Islamic Education

Terbit di Jurnal Tribakti: https://doi.org/10.33367/tribakti.v31i2.1126

Link Journal: https://ejournal.iai-tribakti.ac.id/index.php/tribakti/article/view/1126

dari mulut kemulut saja. Penulis juga hanya menemukan sedikit bukti tulisan-tulisan tentang Kiai Munawaar Gresik seperti Ernawati tahun 2015 (Ernawati, 2015; Ma`arif \& Rofiq, 2019) menulis tentang kepemimpinan Kiai dalam mengembangkan pesantren Daruttaqwa. Muhamamd Anas Ma`arif tahun 2019 yang hanya menulis sedikit biografi serta konsep pendidikannya.

Hasil riset penelitian terdahulu tentang Kiai Munawwar pernah diteliti oleh Ernawati tentang tipe kepemimpinan. Kiai Munawwar dalam memimpin pesantren dan lembaga pendidikan terbagi menjadi tiga tipe kepemimpinan yaitu kepemimpinan karismatik, tradisional dan rasional. Muhammad Anas dan Husnur Rofiq juga meneliti tentang konsep pendidikan Kiai Munawaar dengan berzikir yang menghasilkan bahwa selayaknya murid dan guru mempunyai ikatan batin yang murni agar cahaya hati yang ada didalam hati bersih sehingga akan nampak karakter yang baik. Dzikir menjernihkan pikiran dan hati manusia maka seharusnya murid dan guru selalu berzikir baik dalam pembelajaran atau diluar pembelajaran. Memang tidak banyak yang meneliti Kiai Munawaar akan tetapi secara fakta menyebutkan bahwa Kiai munawwar menjadi rujukan masyarakat gresik dan sekitar dalam hal beribadah dan menimba ilmu.

Sebagai perbandingan dengan riset terdahulu mengenai kiprah kiai dalam dunia pendidikan adalah hasil penelitian Kadariska tentang pendidikan Islam di Sukabumi yang diprakarsai oleh Kiai Sanusi. Selayaknya kiai pasti akan berjuang untuk masyarakat melalui pendidikan Islam. Seperti halnya Kiai Basori Alwi Malang yang berjuang untuk pendidikan Islam dengan berciri khas menulis. Sedangkan Pesantren Sidogiri lebih mengembangkan santrinya kepada kewirausahaan. Seperti halnya Kiai Kholil bangkalan yang berjuang untuk masyarakat sekitar dengan pendidikan Islam.

Dengan demikian agar sejarah dapat tertulis dengan baik dan tidak kesulitan untuk menemukan bukti-bukti sejarah karena masa perjuangan Indonesia tidak banyak yang menulis tentang kiprah pesantren dengan perjuangan Indonesia (Kuntowijoyo, 1987; Mastuhu, 1994), serta masih banyak informan yang masih mengetahui perjuangan dan kiparhanya Kiai Munawwar maka, penulis akan mencoba mendeskripsikan dan menganalisis kontibusi $\mathrm{KH}$ Munawwar terhadap pendidikan Islam di Gresik.

\section{METODE PENELITIAN}

Penelitian ini menggunakan jenis penelitian kualitatif dengan pendekatan historis filosofis. Penelitian historis ini menungkap bagaimana $\mathrm{KH}$ Munawaar Kholil Gresik selama hidupnya melakukan usaha untuk mengembangkan pendidikan Islam di wilayah Gresik dan sekitarnya. Sumber data dalam penelitian ini berupa buku-buku peninggalan, karya tulis, dokumen-dokumen 
serta saksi hidup yang pernah menyaksikan KH Munawaar Kholil (Creswell, 2007; Daliman, 2012). Informan dari penelitian ini adalah saksi hidup yang pernah melihat dan menyaksikan perjuangan Kiai Munawwar Kholil seperti santrinya, keturunanya, koleganya dan orang yang pernah dekat dengan Kiai Munawwar Kholil.

\section{Biografi KH Munawaar Kholil Gresik}

KH Munawwar Adnan Khalil Lahir di Gresik Tahun 1952 bulan November hari jumat pon setelah ashar atau dalam tahun Hijriah lahir 22 Ramadan $1805 \mathrm{H}$ dan Wafat 28 November 2012 di Gresik. Ibundanya bernama nyai Afwah yang nasabnya hingga sampai kepada Sunan Ampel Raden Rahmatullah yaitu Afwah bin Mas Amah binti Sayidah Maryam binti Binti Sihhah bin Abdul Jabbar bin Ahmad bin Pangeran Sambo bin Kyai Joko Tingkir bin binti Mas Murtasimah binti Sunan Drajat binti Subab Ampel Raden Rahmatullah. Sedangkan dari jalur Nyai Afwah juga sampai kepada Sunan Giri Raden Ainul Yaqin. Yaitu: Nyai Afwah binti Mas Amah binti maryam binti Mbah Brojo sampai hingga sunan Giri.

Semasa kecil sebelum belajar ke pondok pesantren beliau belajar kepada ayahandanya sendiri didesa Suci Manyar Gresik, dan kepada Kiai Abdullah Faqih pendiri pondok Mambaus Shalihin Gresik (ayahanda Masbuhin Faqih). Belajar Fiqih, bahasa dan ilmu shorof kepada Syekh Ahmad, Syekh Amin dan belajar Qiraah kepada Syeck Abi Dar dan Syeck Ahmad Mursyid dan juga belajar lain-lain kepada kakeknya yaitu Kiaa Kholil.

Kiai Munawwar belajar di Pondok Pesantren Darul Ubudiyyah Raudhatul Mutaalimin Sawahpoloh Surabaya kepada Kiai Usman Al-Ishaqi (mursid Tarekat Qadiriyah Naqsabandiyah Al-Usmaniyah (Martin, 1992, hlm. 84)) selama 20 tahun dan sekaligus berbaiat kepada Kiai Usman. Nasab kemursyidan Kiai Usman hingga Rasulallah Saw. Ketika Kiai Usman wafat dan digantikan oleh putranya Kiai Asrori Al-Ishaqi, Kiai Munawwar mengikuti baiat lagi (tajdid).

Selama dipesantren Kiai Munawwar melakukan riyadhah dan mujahadah diantaranya: 1) tidak memakan nasi atau apapun yang dari beras selama 10 tahun 2) menjadi abdi ndalem 3) menjadi kepala pondok pesantren 4) istiqamah menyapu ndalem kiai sebelum subuh. 5) menulis risalah-risalah kecil dan dibagikan ke teman-temanya 6) sering tidak memakai sandal 7) ziarah wali 9 dengan berjalan kaki. Kiai Munawwar ketika ziarah ke makam Sunan Ampel pernah melihat Sunan Ampel keluar dari makamnya dan meminta berkah doa kepada Sunan Ampel. Semasa di pesantren Kiai Munawwar pernah menanyakan kepada Kiai Usman perihal pondok kakeknya yang tidak ada penerusnya. Maka jawab dari Kiai Usman adalah tanggung jawab Kiai Munawwar 
Terjemah: The Contribution Of Kiai Munawwar Adnan Kholil Gresike On Islamic Education

Terbit di Jurnal Tribakti: https://doi.org/10.33367/tribakti.v31i2.1126

Link Journal: https://ejournal.iai-tribakti.ac.id/index.php/tribakti/article/view/1126

untuk mengembangkan dan menghidupkan pesantren kakeknya kembali. Biografi ini terdapat disetiap kitab yang ditulis oleh Kiai Munawwar kholil pada bagain belakang setelah daftar pustaka.

\section{Karya KH Munawwar Kholil Gresik}

$\mathrm{KH}$ Munawwar terbukti sangat produktif dalam dunia penulisan dan karya ilmiah. Hal ini dibuktikan dengan beberapa karyanya yang ditulis dalam bahasa Arab dan Bahasa Indonesia. Karya-karyanya antara lain: 1) Badrul Alam ala Nabjï Atam fi Tabwibi al Hikam, Syarah Al-Hikam yang menjelaskan tasawuf 2) Roudbatu al Mubibbin ala Nubdati Qalili min Ibya i Ulum ad Dïn, 3) Tasfiyatu al Qulub wa tahdibiba, Kitab yang menjelaskan tentang kebersihan hati (tasawuf). 4) Manaqib Auliya Al Falibin (Sejarah Rasulallah SAW, Sahabat, dan Tabi in). Seri 1 teridiri dari 3 jilid dan seri 2 terdiri dari 3 jilid. 5) Khoiru Al Zad fi manasik al Hajj 6) Wadhaif al Rabaniyah Wiridan harian untuk santri 7) Khilyatu Al Auliya'(sejarah) 8) Qurrata al Aini Fi Manaqibi Al Qutbu Ar Rabbani, 9) Terjemah Nadzam Al-Imrithi (Ilmu Gramatikal Bahasa) 10) Ajwabu Al Mardhiyah fi Fadbli Mauilidi Khoiru Al-Bariyyah (menjelaskan tentang sejarah maulid, dan keutamaan maulid Nabi Saw). 11) Nafu Al Amimi Sarbu Minbaj Al Qowimi 4 jilid (sarahnya Minbajul Qoqim Ibnu Hajar Al-Haitami, Menjelaskan fikih secara mulptidisiplin). 12) Faidu Al Ilah Fi Fabdli Dikrillah, Mengulas zikir secara menyeluruh.

\section{Kontribusi dalam Pendidikan Formal dan Non Formal dan Pendidikan Life Sklls}

Melihat dari biografi Kiai Munawwar walaupun tidak pernah mengenyam pendidikan formal (Muhammad, 2010) akan tetapi beliau punya semangat dan kemauan kuat mengintegrasikan dzikir dan fikir sehingga teraktualisasikan dalam pendidikan formal dan pendidikan diniah. Tidak hanya pendidikan agama saja tetapi beliau juga mendirikan beberapa pendidikan formal diantaranya mulai dari pendidikan anak usia dini hingga perguruan tinggi. Dari hasil observasi dan wawancara dengan (Ahmad Taufiq, surat, 2020) sebagai berikut:

"Di pondok pesantren Daruttaqwa Gresik ini diresmikan sejak tahun 1989 oleh bupati H Amiseno dan sejak itulah pendidikan di Daruttaqwa berkembang hingga saat ini. Yayasan Al-Munawwar memiliki lembaga dari anak usia dini hingga perguruan tinggi. Tidak hanya pendidikan formal saja pendidikan non formal juga terdapat dalam naungan yayasan seperti Taman Pendidikan Al-Qur an TPQ dan Pendidikan Diniah".

Perjuangan membuat pesantren serta lembaga-lembaga yang berada didalamnya tentunya bukanlah hal yang mudah dan hal ini tentunya membutuhkan perjuangan (Kadariska, 2018; Qomar, 2005; Rohmawati, 2015). Berawal diresmikan oleh Bupati tahun 1987 Kiai Munawwar mengajar 
santri-santrinya dengan pendidikan pesantren klasik seperti mengaji, baca kitab kuning, pendidikan diniah dan pendidikan life skill atau istilah kultur pesantren disebut dengan kbidmah. Santri yang datang dan belajar kepada Kiai Munawwar kala itu tidaklah banyak dan beliaupun sangat sabar mengajar santrinya walau hanya satu dua orang saja. Karena beliau adalah santri yang taat kepada gurunya, Kiai Munawwar melaksanakan apa yang pernah dikatakan oleh Kiai Ahmad Asrori Al-Ishaqi. "kalau ingin menjadikan pesantren ini maju dan berkembang, maka buatlah lembaga pendidikan formal'(Ernawati, 2015, hlm. 99).

Sebagai santri yang tunduk dan patuh kepada guru mursyidnya Kiai Munawwar bermula mendirikan lembaga formal Madarasah Tsanawiyah Daruttaqwa tahun 1994. Beliau di bantu oleh santri dan kolega-koleganya untuk mencari siswa agar mau belajar dan bersekolah di madarsah pesantren Daruttaqwa. Beridirinya lembaga formal tersebut juga diikuti oleh lembaga lainnya seperti Madrasah Aliyah Daruttaqwa setingkat SMA, Madrasah Ibtidaiyah setingkat Sekolah Dasar dan Roudlatul Athfal setingkat Taman Kanak-Kanak (TK). Tidak puas begitu saja, pada tahun 1998 Kiai Munawwar menggagas untuk mendirikan sekolah tinggi Islam dikarenakan untuk menampung lulusan madrasah aliyah yang tidak sanggup untuk kuliah diluar lingkungan Pesantren. Hingga pada Tahun 2000 (Surat Keputuan, 2000) penyelenggaraan sekolah tinggi sudah dimiliki oleh Sekolah Tinggi Agama Islam Daruttaqwa program pendidikan Agama Islam (PAI).

Pada saat ini Pondok Pesantren Daruttaqwa yang didirikan oleh Kiai Munawwar Kholil memiliki banyak lembaga-lembaga pendidikan yang dinaungi oleh Yayasan Al-Munawwar, diantaranya adalah: 1) Pendidikan anak usia dini 2) Madrasah Ibtidaiyah (MI Daruttaqwa) 3) Madrasah Tsanwiyah Daruttaqwa 4) SMP Daruttaqwa 5) Madrasah Aliyah Daruttaqwa 6) SMA Daruttaqwa 7) SMK Daruttaqwa. 8) Sekolah Tinggi Agama Islam (STAI) Daruttaqwa. Disamping lembaga formal pesantren Daruttaqwa juga memiliki lembaga non formal seperti: 1) TPQ Daruttaqwa 2) Madrasah Diniah 3) lembaga kursus bahasa. 4) pendidikan life skils.

Adapun yang menjadi ciri khas dari pesantren Daruttaqwa adalah pendidikan life skill yang diberikan oleh Kiai Munawwar kepada santri-santrinya. Berbagai macam keahlian yang diajarkan Kiai Munawwar adalah untuk membentuk kemandirian santri sejak dini. Hal ini tentunya senada dengan tujuan pondok pesantren secara umum bahwa disamping membentuk manusia tafaquh $f i$ $\operatorname{din}($ Hasan, 2016, hlm. 72; Rahmat, 2018) tetapi juga diberikan bekal keahlian untuk menghadapi tantangan dimasyarakat secara mandiri (Kawakib, 2016; Kesuma, 2017; Said, 2006, hlm. 216). Seperti apa yang katakan oleh Alumni Pesantren Daruttaqwa bahwa: 
"Yai Munawwar dulu mengajarkan santrinya dengan khidmah, seperti kerja kuli bangunan, roan, menggembala sapi, dan lain sebagainya adalah untuk membentuk santri yang mampu menghadapi masyarakat kelak. Yai Dawuh 'Santri iku kudu iso sembarang, nek kumpul wong dodolan yo kudu iso bahas dodolan, nek kumpul wong blantik yo kudu iso blantik, opo maneh ngaji, wajib iso. Urip neng masyarakat iku gake mong nabwu lan shorof tetapi macem-macem. Dan yang paling penting dari kbidmah adalah keberkaan dan keridhoan yai. Karena dulu Kiai Munawaar waktu mondok juga tidak hanya sekedar mengaji saja tetapi juga mampu menjadi abdi dalem, tukang sapu, tukang cuci baju kiai dan juga menjadi kepala pondok”(Lesmana, surat, 2020).

Pendidikan life skill yang diajarkan oleh Kiai Munawwar tidak hanya sekedar mengisi kegiatan kosong dipesantren melainkan sebuah kegiatan yang mampu membentuk santri untuk hidup mandiri, dewasa dan kuat menghadapi tantangan hidup. Kegiatan life skill seperti: menukang, menyapu, mengecor, wirausaha, perairan, kelistrikan, berdagang, penyiar radio dan lain sebagainya. Kegiatan life skill secara kultural di Pesantren Daruttaqwa disebut sebagai khidmah (membantu). Kulutur kbidmah dalam pesantren ini dipercaya sebagai nilai positif untuk menambah keberkahan dalam mencari ilmu dipesantren. Sehingga kebanyakkan santri yang belajar dipesantren ini mempunyai keahlian yang berbeda-beda. Hal ini senada dengan Agil Siraj (Said, 2006, hlm. 205) bahwa santri tidak hanya belajar dan memperoleh ijasah saja melainkan mampu tunduk dan patuh kepada kiai sehingga memperoleh hikmah dan barakah (Nasr, t.t., hlm. 119; Syarif, 2013, hlm. 29; Zamhari, 2010, hlm. 87).

Pendidikan kecakapan hidup life skill di Pesantren Daruttaqwa tidak masuk dalam kurikulum akan tetapi sudah menjadi tradisi bahwa melakukan suatu keahlian dipesantren merupakan bekal hidup di masyarakat. Hal ini tentunya sebagai upaya pendidikan Islam khususnya pesantren memperkecil jarak antara pendidikan secara teoretis dan kehidupan seharihari (Noor, 2015, hlm. 3-4). Pesantren juga mengajar santrinya memahami realitas untuk melihat pada kehidupanya nyata lewat keahlian yang diajarkan oleh Kiai Munawwar. Artinya bahwa upaya Kiai Munawwar mengajarkan berbagai macam keahlian dan kecakapan akdemik kepada santrinya untuk bekal didunia dan di akhirat. Hal ini senada dengan definisi pendidikan kecakapan hidup menurut Anwar yang dikutip oleh Rohmah bahwa pendidikan kecakapan hidup adalah memberikan bekal hidup praktis dan kemampuan siap pakai kepada peserta didik (Rohmah, 2017, hlm. 179) 
Berikut adalah pendidikan life skill yang diajarkan oleh Kiai Munawwar Kholil Gresik yaitu:

Tabel 1.1 Pendidikan Life Skill yang diajarkan Kiai Munawwar Kholil Gresik

\begin{tabular}{|c|c|c|}
\hline No & $\begin{array}{l}\text { Bentuk Pendidikan Life } \\
\text { Skill }\end{array}$ & Keterangan \\
\hline 1 & Wirausaha/Entrepeneur & $\begin{array}{l}\text { Santri diberi tanggung jawab penuh untuk mengelola } \\
\text { kantin dengan baik tanpa meninggalkan kewajiban yang } \\
\text { lain. }\end{array}$ \\
\hline 2 & Pertukangan & $\begin{array}{l}\text { Santri dibekali dengan ketahanan fisik serta kemampuan } \\
\text { untuk mendesain bangunan. Keahlian ini yang sering } \\
\text { diperhatikan oleh Kiai Munawwar disamping untuk } \\
\text { pengembangan pesantren tetapi juga menjadikan santri } \\
\text { lebih piawai untuk melakukan pekerjaan. }\end{array}$ \\
\hline 3 & $\begin{array}{l}\text { Pengelolaan } \\
\text { Reporter, Penyiar. }\end{array}$ & $\begin{array}{l}\text { Santri secara penuh mengelola manajemen radio sehingga } \\
\text { santri mampu dan mengetahu tata kelola dan etika } \\
\text { publikasi dan jurnalistik. }\end{array}$ \\
\hline 4 & Mengajar & $\begin{array}{l}\text { Santri yang sudah lulus sarjana mendapat kesempatan } \\
\text { untuk mengajar di lembaga formal. }\end{array}$ \\
\hline 5 & Peternakan & $\begin{array}{l}\text { Santri secara penuh diberikan tanggung jawab mengelola } \\
\text { peternakan sapi dan kambing tanpa lupa meninggalkan } \\
\text { kewajiban belajar. Hal ini juga sama seperti dalam buku } \\
\text { biografi Kiai Munawwar bahwa beliau pernah } \\
\text { menggembala kambing seperti para Nabi(Muhammad } \\
\text { Munawwar, 2007, hlm. Biografi). }\end{array}$ \\
\hline 6 & Pengelolaan Klinik & $\begin{array}{l}\text { Santri diberikan tanggung jawab mengelola klinik dan } \\
\text { apotik pesantren. santri juga ditunjuk untuk membantu } \\
\text { dokter dan bidan. (hingga Kiai Munawwar pernah ingin } \\
\text { mendirikan Sekolah Tinggi Kesehatan)(Ernawati, 2015, hlm. } \\
\text { 99) }\end{array}$ \\
\hline 7 & Driver (Pengemudi) & $\begin{array}{l}\text { Santri diberi tanggung jawab untuk mengelola travel } \\
\text { pesantren. } \\
\text { Santri juga diberikan tanggung jawab penuh untuk } \\
\text { mengelola setiap kendaraan (truck) pesantren. }\end{array}$ \\
\hline 8 & Perkebunan & $\begin{array}{l}\text { Santri diberikan wawasan dan pengetahuan serta praktik } \\
\text { pengelolaan perkebunan. Pesantren mengelola kebun } \\
\text { mangga, sayur dan umbi-umbian. }\end{array}$ \\
\hline 9 & Menjahit & $\begin{array}{l}\text { Santri dengan keahlian ini sanggup meningkatkan ekonomi } \\
\text { pesantren karena baju seragam santri ini dijahit oleh santri } \\
\text { bagian penjahit. }\end{array}$ \\
\hline
\end{tabular}


Terjemah: The Contribution Of Kiai Munawwar Adnan Kholil Gresik On Islamic Education

Terbit di Jurnal Tribakti: https://doi.org/10.33367/tribakti.v31i2.1126

Link Journal: https://ejournal.iai-tribakti.ac.id/index.php/tribakti/article/view/1126

Selian diatas terdapat hal unik yang dilakukan oleh Kiai Munawwar yaitu mengajarkan santri-santri agar mampu melakukan riyadah dan mujahadah. Kiai munawar selau memberikan pesan kepada santri-santrinya agar tidak suka membeli makanan diluar lingkungan pesantren. hal ini tentunya bukan tanpa sebab melainkan untuk stabilitas pesantren serta mereduksi kenakalan santri yang suka keluar pesantren tanpa izin. Senada dengan Az Zarnuji yang terdapat dalam kitab ta 'limul mutaaliim bahwa seorang dalam kondisi belajar harus mengurangi makanan dari pasar serta menghindari hal yang kurang bersih (Al-Zarnuji, t.t., hlm. 14).

Ciri khas pendidikan yang dilakukan oleh Kiai Munawwar yaitu tawassuth (tidak terlalu fikih dan tidak terlalu tasawuf). Walaupun beliau seorang sufi penganut tarekat yang taat akan tetapi dalam kehidupan sehari-hari dan cara mendidik selalu memakai cara yang tengah-tengah. Kiai Munawwar lebih suka kepada seorang yang melakukan ibadah secara istiqamah dan rutin. Bahkan diberbagai kesempatan beliau sering berpesan kepada santri-santrinya bahwa "seorang yang abli tasawnf itu tidak kagetan atau mudah takjub dengan hal-hal di dunia"(Lesmana, surat, 2020). Pernyataan diatas sesungguhnya menunjukan bahwa Allah maha membuat sesuatu sehingga sebagai hamba yang taat, kejadian di dunia adalah sebagai tanda kebesaraNya.

\section{Tujuan Pendidikan}

Secara umum Kiai Munawwar mempunyai tujuan pendidikan yang sering disebutkan dalam berbagai kesempatan yaitu: 1) jadikan seorang ulama` dan 2) menjadi seorang konglomerat yang dermawan. Hal ini juga diceritakan oleh salah satu santrinya "mondok iku nek moleh jadio kiai nek gak ngono jadio wong sing sogeh tur dermawan" (Lesmana, surat, 2020). Tujuan pendidikan yang digagas oleh Kiai Munawwar memang tidak spesifik akan tetapi itu sudah mencakup secara ukhrowi dan secara duniawi. Senada dengan (Arifin, 2006) bahwa pendidikan Islam itu mencakup tujuan keagamaan (ghrdu dini) dan tujuan duniawi (gardu dunya). Tujuan pendidikan pesantren kebanyakan sesuai dengan kepribadian kianya dan latar belakang kianya belajar (Solichin, 2018).

Kiai Munawwar dalam melaksanakan tujuan pendidikan pesantren memiliki karakteristik sebagai berikut: 1) Akhlak lebih penting dari pada hanya sekedar berilmu tetapi tidak berakhlak. 2) Dalam menuntut ilmu mencari keberkahan guru adalah tujuan utama, ketika keberkahan diperoleh walau sedikit saja maka akan menjadikan bahagia dunia dan akhirat 3) santri harus mampu melakukan apa saja (fleksibel). 4) jangan lupa dengan sejarah, artinya seorang santri harus tahu asal usulnya. 


\section{Karya Tulis Sebagai Identitas dan Kerpakaran}

$\mathrm{KH}$ Munawwar dengan kesibukanya sebagai Kiai dan sering mendapat undangan dari masyarakat beliau juga sangat gemar menulis kitab fikih, tasawuf, sejarah dan sebagainya. Hal ini bukan tanpa dasar melainkan hasil wawancara dengan abdi dalem beliau semasa hidupnya. Menurutnya pemaparanya:

"Kiai Munawwar saking suka dan senang dengan dunia pendidikan beliau menulis beberapa karya fenomenal seperti kitab fikih, tasawuf dan sejarah. Beliau menulis dikala menjelang subuh sekitar jam 3-an. Sebelum menulis beliau shalat malam dahulu dan dilanjutkan dengan menulis dengan berbagai banyak referensi. Referensinya adalah kitab-kitab mu tabarah yang dimiliki beliau selperti Tafsir kabir, jam 'ul jawami, musnad abmad dan lain sebagainya. Banyak sekali kitabnya. Kecintaanya dengan menulis dan membaca kitab beliau tunjukan dengan selalu membawa kitab kemanapun dan dimanapun. Dalam kendaraan (mobil) selalu ada kitab yang dibawa oleh beliau (Andik Firmansyah, surat, 2020).

Dari pemaparan diatas patut diteladani adalah bahwa seorang kiai yang sibuk dengan kegiatan mengajar dan khadimul ummah tetap masih sangat mencintai menulis dan membaca kitabkitab mua tabarah. Tidak banyak ditemui seorang Kiai dengan kesibukanya dengan ummat tetapi masih sanggup menulis karya-karya (Amrullah, 2013a) yang sangat menumental. Hal yang membuat unik dari Kiai munawar adalah karyanya yang semuanya berbasa Arab. Padahal menurut Bruinessen kecenderungan ulama modern lebih banyak menulis karyanya dengan bahasa Indonesia (Martin, 2012, hlm. 78). Walaupun sudah pandai dan menciptakan beberapa karya yang banyak Kiai Munawwar tetap tawadu hal ini dibuktikan dengan karya beliau yang pernah mendapat restu dan kata pengantar dari (KH Maimun Zubair memuji KH Munawar dengan sebutan Ulama Tasawuf Muhammad Munawwar, 2007).

Keahlian menulis dan sabar melayani ummat tampaknya menjadikan seorang Kiai lebih disukai dan dipercaya oleh masyarakat (Arwani, 2016; Faris, 2015). Bahkan masyarakat juga banyak yang berduyun-duyun untuk meminta nasehat, doa, barokah serta memondokan anaknya di pesantren tersebut. Peran seperti itulah yang dilakukan oleh kiai agar masyarakat awam mempunyai rujukan dalam beragama (Amrullah, 2013b, hlm. 41).

Karya yang telah ditulis oleh Kiai Munawwar sampai saat ini masih dikaji dan dipelajari oleh santri-santri Daruttaqwa. Penganjian bandongan dan wetonan yang dilaksanakan di pesantren dilakukan bergantian oleh putra-putra beliau beserta Ustadz senior yang pernah mendapat mandat dari Kiai Munawwar. Menurut penulis terdapat karya fenomenal dari Kiai Munawwar adalah kitab Naf ul Amim yang terdiri dari 4 jilid dan disetiap satu jilid terdiri dari 600 halaman. Kitab Naf ul amin ini mensyarahi kitab minhajul Qowim karya dari Ibnu Hajar Al-Haitami 
Terjemah: The Contribution Of Kiai Munawwar Adnan Kholil Gresike On Islamic Education

Terbit di Jurnal Tribakti: https://doi.org/10.33367/tribakti.v31i2.1126

Link Journal: https://ejournal.iai-tribakti.ac.id/index.php/tribakti/article/view/1126

dan mengulas fikih berbagai perspektif mulai sejarah, fikih empat madzhab, kontradiksi fiqih, dan fikih konstektual(Muhammad, 2009a). Walaupun sudah ditulis menjadi empat jilid akan tetapi karya ini belum sempat diselesaikan dengan sempurna karena Kiai Munawwar telah dilpanggil oleh Allah pada Tanggal 28 November 2012.

Karya-karya yang di telah ditulis oleh Kiai Munawwar menunjukan bahwa dunia pesantren sangatlah dinamis. Bahkan dalam kurikulum pesantren karya-karya Kiai Munawwar dimasukan dalam pembelajaran. Karya tulis Kiai menunjukan bahwa dirinya memiliki identitas dan kepakaranya sehingga menjadi rujukan bagi masyarakat awam (Amrullah, 2013b). Kiai Munawwar disamping mendapat julukan sebagai Kiai yang sabar beliau juga mendapat pujian dari beberapa Kiai di Jawa Timur dan Jawa Tengah sebagai Kiai yang pandai menulis kitab walaupun beliau tidak pernah mengenyam pendidikan di semenajung Arabiyah (belajar dipesantren yang diasuh KH Usman Al-Ishaqi Sawahpuluh Surabaya selama 20 Tahun (Kieswono, t.t.)).

Salah satu karya Kiai Munawwar yang terbentuk oleh latar belakang dan kehidupan keseharian beliau adalah Faidu Al Ilab (Kebanyakan karya Kiai atau Ulama dipengaruhi oleh latar belakang pendidikan dan keseharianya.; Wiratdoni, 2018). Kitab ini mengupas tentang pentingnya zikir yang ditinjau dan merujuk dari beberapa kitab mutabarah seperti Tafsir Kabir, Tafsir Al-Qurtubi, Kutub As Sitah, Tarik Al Baghdad. Tarikh ad dimisqoq dan kitab monumental karya ulama` klasik yang lainya(Muhammad Munawwar, 2011). Keseharian Kiai Munawar adalah mengajar santri, mengikuti majelis zikir, menghadiri undangan dari masyarakat berbagai kalangan, mengawasi santri dalam mengembangkan skil dan berbagai kegiatan positif lainya. Keseharinya hanya ditujukan kepada kegiatan positif dengan mencari kridhoan Allah Swt. Seperti apa yang telah disampaikan dalam rekaman pengajian dan tertulis dalam Kitab Faid Al Ilah tentang zikir yaitu "Semua kegiatan positif seperti berdagang, mengajar, bertani, menukang dan lain sebagianya dengan diniatkan kepada Allah maka hal tersebut disebut sebagai zikir”(Muhammad, 2009b).

\section{Mendidik dengan Metode Bercerita (Qisoh)}

Bercerita adalah salah satu dalam metode mendidik (Hidayat, 2018), dalam pendidikan karakter bercerita juga salah satu strategi untuk internalisasi nilai-nilai dan menjadi jembatan komunikasi antara peserta didik dengan guru orang tua dan mayarakat (Nielsen, 2006; Rahman, 2013). Bercerita adalah metode pendidikan yang sangat digemari oleh setiap orang, hal ini terbukti dengan cara yang dilakukan oleh Kiai Munawwar dalam berceramah dan mendidik santri. Hal ini senada dengan apa yang dipaparkan oleh Husnur Rofiq Alumni Pondok Pesantren Daruttaqwa bahwa 
"Kiai Munawwar itu ahli dalam bercerita. Dalam berbagai kesempatan ketika mengajar dan berceramah isi dan penyampaian makna yang diberikan banyak menggunakan cerita-cerita seorang wali, cerita motivasi, dan cerita teladan yang ada di masalalu. Yang sering saya ingat ketika belajar dipesantren Daruttaqwa adalah cerita Shodin. Shodin adalah santri yang tidak ganteng atau tampang bahkan dibilang tidak enak dipandang, akan tetapi dia adalah orang yang giat dalam belajar, menghafal alfiah saja dalam waktu satu minggu. Singakat cerita adalah bahwa Shodin seorang santri yang mendapatkan berkah dari Kiainya karena sungguh-sungguh dalam belajar".

Cerita yang dipaparkan oleh kiai Munawwar disampaikan dengan cara humor dan santai sehingga banyak dari orang yang mendengarkan antusias sekali. Ahli dalam bercerita sejarah Islam tidak hanya dalam menjelaskan ketika mengaji dan ceramah tetapi Kiai Munawwar menunjukan dengan menulis Kitab Al-Auliya Al Falibin yang terdiri dari 2 edisi. Setiap edisi terdiri dari tiga jilid dan disetiap satu jilid terdiri dari 600 sampai dengan 700 halaman. Isi dari kitab ini adalah kisah tentang Nabi Saw, Sabahat Nabi, tabiin dan tabiit.

Kiai Munawwar memiliki persamaan dengan beberapa kiai lain dalam mengembangkan pendidikan Islam yaitu dalam menerapkan karya tulisnya sebagai materi kurikulum dalam pengajian. Cara ini juga dilakukan oleh Kiai Asrori, dan kiai Bashori Alwi Malang. Kesamaan ini kemungkinan dikarenan ketiga kiai tersebut sama-sama belajar pada Kiai Usman Al-Ishaqi Surabaya. Kesamaan lainya adalah beberapa kiai sangat menyukai dunia karya tulis. Setiap kiai mempunyai kepakaran masing-masing seperti halnya Kiai bashori alwi Malang yang ahli dalam bidang qiraat, kiai Asrori Al-Ishaqi pakar dalam bidang tasawuf dan tarekat sedangkan Kiai munawaar Khalil ahli dibidang sejarah dan tasawuf yang artinya metode pendidikan yang disampaikan juga berbeda.

\section{KESIMPULAN}

Kiai Munawwar memberikan kontribusi yang sangat banyak bagi dunia pendidikan Islam di Gresik hal ini bisa dilihat dari lembaga-lembaga di bawah Yayasan Al-Munawwar yang teridiri dari pendidikan anak usia dini hingga perguruan tinggi. Tidak hanya bentuk lembaga saja tetapi cara mendidik santri yang sudah menjadi tradisi dilingkungan pesantren yaitu pendidikan life skill (khidmah). Selain itu Kiai Munawwar adnan Kholil Gresik juga memberikan kontribusi dengan cara menulis kitab-kitab dari bahasa Arab. Karya tulis Kiai Munawwar juga menjadi bagian dari kurikulum pendidikan di Pesantren Daruttaqwa. Karya tulisnya menunjukan bahwa kapasitas sorang kiai dan kepakaranya dibidang agama sehingga menjadi rujukan masyarakat. Karya-karya 
Terjemah: The Contribution Of Kiai Munawwar Adnan Kholil Gresik On Islamic Education

Terbit di Jurnal Tribakti: https://doi.org/10.33367/tribakti.v31i2.1126

Link Journal: https://ejournal.iai-tribakti.ac.id/index.php/tribakti/article/view/1126

Kiai Munawwar juga memberikan inspirasi bagi masyarakat pada umumnya dan terkusus santrisantrinya bahwa manusia berkualitas adalah seorang yang meninggalkan karya tulis.

\section{REFERENSI}

Ahmad Taufiq. (2020). Wawancara, Alumni Pondok Pesantren Daruttaqwa Gresik [Surat].

Al-Zarnuji, B. I. (t.t.). Ta 'limul Muta 'alim. Al-Hidayah.

Amanda, C. (2016). "Religi" sebagai Pendekatan Desain untuk Fasilitas Wisata di Kota Gresik. Jurnal Sains dan Seni ITS, 4(2).

Amrullah, A. M. K. (2013a). Perubahan Dan Perkembangan Model Pesantren. El-Hikmah, O(0). http://ejournal.uin-malang.ac.id/index.php/elhikmah/article/view/2238

Amrullah, A. M. K. (2013b). Kontribusi Karya Tulis Kiai Basori Alwi Terhadap Pengembangan Wawasan Keagamaan Masyarakat. Ulul Albab Jurnal Studi Islam, 13(1), 35-48. https://doi.org/10.18860/ua.v0i0.2381

Andik Firmansyah. (2020). Wawancara, Kepala Pondok Pesantren Daruttaqwa Tabun 2020 [Surat].

Arifin, H. M. (2006). Ilmu pendidikan Islam: Suatu tinjauan teoritis dan praktis berdasarkan pendekatan interdisipliner. Bumi Aksara.

Arwani, W. (2016). Kiai Pesantren Dan Kontribusinya Dalam Mengembangkan Pluralitas Keberagamaan Dan Toleransi Di Kabupaten Cirebon. Holistik, 15(1). https://doi.org/10.24235/holistik.v15i1.434

As’ad, M. (2015). Tajdīd al-Tarbīyah al-Islāmīyah 'inda al-Shaykh al-H̄ājj Imam Zarkasyi. Studia Islamika, 22(2), 333-368. https://doi.org/10.15408/sdi.v22i2.1922

Chairudin, M. (2017). Strategi Pengembangan Pondok Pesantren Qomaruddin Gresik. Jurnal Ilmu Pendidikan Islam, 15(1), 73-88.

Counter_webgresik. (2016). https://www.powr.io/hit-counter/u/f0c2dd77_1501400614

Creswell, J. W. (2007). Qualitative inquiry \& research design: Choosing among five approaches (2nd ed). Sage Publications.

Daliman, A. (2012). Metode penelitian sejarah. Penerbit Ombak.

Dhofier, Z. (2011). Tradisi pesantren: Studi pandangan hidup kyai dan visinya mengenai masa depan Indonesia (Cet. 8 rev). LP3ES.

Ernawati. (2015). Kepemimpinan Kh. Munawar Adnan Kholil Dalam Mengembangkan Pondok Pesantren Daruttaqwa Suci Gresik Tahun 1987-2012. Avatara, 3(2). https://jurnalmahasiswa.unesa.ac.id/index.php/avatara/article/view/11496

Faridatin, N. (2016). Kota Gresik Sebagai Kota Santri "Implikasi Sebagai City Branding." Thaqafiyyat: Jurnal Bahasa, Peradaban Dan Informasi Islam, 17(1), 106-121.

Faris, A. (2015). Kepemimpinan Kiai dalam Mengembangkan Pendidikan Pesantren. 'Anil Islam: Jurnal Kebudayaan Dan Ilmu Keislaman, 8(1), 123-144.

Hasan, N. (2016). Model Pembelajaran Berbasis Pondok Pesantren Dalam Membentuk Karakter Siswa Di Pondok Pesantren Raoudhotut Tholibin Rembang Jawa Tengah. Wahana Akademika: Jurnal Studi Islam dan Sosial, 3(2), 92-110.

Hidayat, A. (2018). Rekonstruksi Pendidikan Islam Dalam Perubahan Mindset Masyarakat Gunung Kemukus. Edukasia: Jurnal Penelitian Pendidikan Islam, 13(2). https://doi.org/10.21043/edukasia.v13i2.3636 
Kadariska, S. (2018). Perjuangan K.H. Ahmad Sanusi dalam Memajukan Pendidikan Islam di Sukabumi Tahun 1922-1950 [Diploma, UIN Sunan Gunung Djati Bandung]. http://digilib.uinsgd.ac.id/13700/

Kawakib, A. (2016). Tujuan Pendidikan Islam. Al-Fitrah, 10(1).

Kesuma, G. C. (2017). Refleksi Model Pendidikan Pesantren dan Tantangannya Masa Kini. Tadris: Jurnal Keguruan Dan Ilmu Tarbiyah, 2(1), 67-79. https://doi.org/10.24042/tadris.v2i1.1740

Kieswono. (t.t.). Biografi Kh. M. Munawwar Adnan Kholil |Ponpes Daruttaqwa Suci Gresik. Biografi Kh. M. Munawwar Adnan Kholil | Haul Akbar Ponpes Daruttaqwa Suci Gresik. Diambil 24 Februari 2020, dari http://haulakbar.blogspot.com/2018/02/biografi-kh-mmunawwar-adnan-kholil.html

Kompasiana. (2018). Julukan Gresik Kota Santri. Kompasiana. https://www.kompasiana.com/hana5301/5d8a391f0d823073b6406072/julukan-gresikkota-santri

Kuntowijoyo. (1987). Budaya dan Masyarakat. Tiara Wacana.

Lesmana. (2020). Wawancara: Alumni Pondok Pesantren Daruttaqwa [Surat].

Ma`arif, M. A., \& Rofiq, M. H. (2019). Dzikir Dan Fikir Sebagai Konsep Pendidikan Karakter: Telaah Pemikiran KH. Munawwar Kholil Al-Jawi. Tadrib, 5(1), 1-20. https://doi.org/10.19109/tadrib.v5i1.3066

Martin, V. B. (1992). Tarekat Naqsabandiyah DI Indonesia (1 ed.). Mizan.

Martin, V. B. (2012). Kutab Kuning Pesantren dan Tarekat (1 ed.). Gading Publising.

Mastuhu. (1994). Dinamika sistem pendidikan pesantren: Suatu kajian tentang unsur dan nilai sistem pendidikan pesantren (2 ed.). INIS.

Muhammad, M. K. (2009a). Naf u Al Amimi Sarbu Minhaj Al Qowimi. Daruttaqwa.

Muhammad, M. K. (2009b). Pengajian Faid Al-Ilab [MP3].

Muhammad, M. K. (2010). Manaqib Auliya`Al Falibin. Daruttaqwa.

Muhammad Munawwar, K. (2007). Badrul Alam, Ala Nabji Al Atam fi Tabwibi Al Hikam. PP Daruttaqwa.

Muhammad Munawwar, K. (2011). Faidul Ilah fi Fadli Diqkeri Allah. PP Daruttaqwa.

Nasir, M. R., \& Abdushomad, M. A. (2005). Mencari tipologi format pendidikan ideal: Pondok pesantren di tengah arus perubahan (Cet. 1). Pustaka Pelajar.

Nasr, S. H. (t.t.). The_heart_of_islam. 227.

Nielsen, T. W. (2006). Towards a pedagogy of imagination: A phenomenological case study of holistic education. Ethnography and Education, 1(2), 247-264.

Noor, A. H. (2015). Pendidikan Kecakapan Hidup (life Skill) Di Pondok Pesantren Dalam Meningkatkan Kemandirian Santri. Empowerment: Jurnal Ilmiah Program Studi Pendidikan Luar Sekolah, 4(1), 1-31. https://doi.org/10.22460/empowerment.v4i1p1-31.553

Qomar, M. (2005). Pesantren: Dari transformasi metodologi menuju demokratisasi institusi. Erlangga.

Rahman, M. M. (2013). Metode bercerita membentuk kepribadian muslim pada anak usia dini. ThufuLa.

Rahmat, M. (2018). Kiai Hasan Ulama Mursyid Tarekat Shaththariah As a Pioneer of Modern Pesantren. Jurnal Pendidikan Islam, 7(1), 1-22. https:/ / doi.org/10.14421/jpi.2018.71.1-22

Ramayulis. (2012). Sejarah Pendidikan Islam, Napaktilas Perubahan Konsep, Filsafat dan Metodelogi Pendidikan Islam dari Era Nabi Saw sampai Ulama` Nusantara. Kalam Mulia. 
Riyadi, A. K. (2017). The Concept of Man in Ahmad Asrori's Anthropology of Tasawuf. Journal of Indonesian Islam, 11(1), 223-246-246. https://doi.org/10.15642/JIIS.2017.11.1.223-246

Rohmah, S. (2017). Manajemen Pengembangan Kecakapan Hidup Untuk Meningkatkan Kemandirian Santri Di Pesantren. TADBIR MUWAHHID, 1(2), 177-182. https://doi.org/10.30997/jtm.v1i2.1093

Rohmawati, D. (2015). Perjuangan K.h. Muhammad Sholeh Dalam Mengembangkan Pondok Pesantren Attanwir Talun Sumberrejo- Bojonegoro Tahun 1933- 1992. Avatara, 3(2), Article 2. https://jurnalmahasiswa.unesa.ac.id/index.php/avatara/article/view/11497

Said, A. S. (2006). Tasawnf Sebagai Kritik Sosial. Mizan.

Sayono, J. (2005). Perkembangan Pesantren di Jawa Timur. Babasa dan Seni.

Solichin, M. M. (2018). Pendidikan Islam Moderat Dalam Bingkai Kearifan Lokal. Jurnal Mudarrisuna: Media Kajian Pendidikan Agama Islam, 8(1), 174-194. https://doi.org/10.22373/jm.v8i1.2950

Sunyoto, A. (2016). Atlas Wali Songo: Buku pertama yang mengungkap Wali Songo sebagai fakta sejarah. Kerjasama Pustaka IIMaN, Trans Pustaka, dan LTN PBNU.

Surat Keputuan. (2000). Surat Keputusan Pendirian Sekolah Tinggi Daruttaqwa Gresik.

Syafaah, A. (2016). Peran Dan Perjuangan Kiai Masykur Di Desa Karangsari Weru Cirebon (1835-1961). Holistik, 1(2), 215-227. https://doi.org/10.24235/holistik.v1i2.1124

Syarif, Z. (2013). Mitos Nilai-Nilai Kepatuhan Santri. Tadris: Jumal Pendidikan Islam, 7(1), 19-30.

Takdir, M. (2016). Kontribusi Kiai Kholil Bangkalan dalam Mengembangkan Tasawuf Nusantara. 'Anil Islam: Jurnal Kebudayaan Dan Ilmu Keislaman, 9(2), 268-299.

Wasid, \& Mahsun. (2018). Kiai Abdul Hamid Pasuruan Dan Kontribusinya Untuk Moderasi Islam. Al Fikrah, 1(1), 71-81.

Wiratdoni, W. (2018). Analisis Konsep Penciptaan Seni Lukis Kaligrafi Islami Karya Abmad Mustofa Bisri. Zamhari, A. (2010). Rituals of Islamic spirituality a study of Majlis Dhiker groups in East Java. ANU E Press.

Zarkasyi, H. F. (2018). Appraising the Moderation Indonesian Muslims with Special Reference to Muhammadiyah and Nahdlatul Ulama. Addin, 12(1), 1-30. 